BNL - 60755

Informal Report

\title{
DISCLAIMER
}

This report was prepared as an account of work sponsored by an agency of the United States Government. Neither the United States Government nor any agency thereof, nor any of their employees, makes any warranty, express or implied, or assumes any legal liability or responsibility for the accuracy, completeness, or usefulness of any information, apparatus, product, or process disclosed, or represents that its use would not infringe privately owned rights. Reference herein to any specific commercial product, process, or service by trade name, trademark, manufacturer, or otherwise does not necessarily constitute or imply its endorsement, recommendation, or favoring by the United States Government or any agency thereof. The views and opinions of authors expressed herein do not necessarily state or reflect those of the United States Government or any agency thereof.

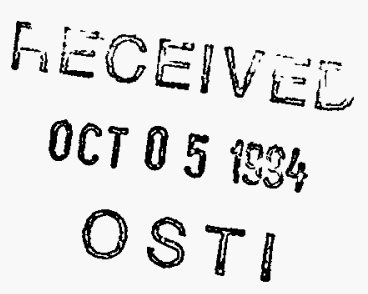

\section{Resonance Raman Spectroscopy of Volatile Organics - Carbon Tetrachloride}

\author{
R. E. Barletta and J. T. Veligdan
}

September 1994

\section{Engineering Research and Development Division Department of Advanced Technology}

\author{
Brookhaven National Laboratory \\ Upton, NY 11973
}

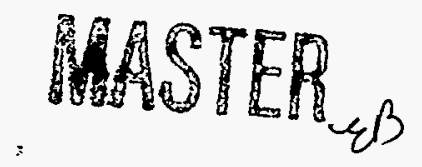




\begin{abstract}
Volatile organic chemicals are a class of pollutants which are regulated at very low levels by the EPA. Consequently a need exists as a part of site remediation efforts within DOE to develop technologies which will allow for the in situ monitoring of these chemicals. Resonance Raman spectroscopy is a potential technique to accomplish this if the resonance enhancement is sufficiently high. Carbon tetrachloride was selected as a test case. Measurements under resonance conditions at $248 \mathrm{~nm}$ showed an enhancement factor of $2 \times 10^{4}$. Using this value an estimate of the sensitivity for both in situ and remote monitoring of $\mathrm{CCl}_{4}$ was made. It was concluded that resonance Raman could be used to detect these chemicals at levels of regulatory interest.
\end{abstract}




\section{DISCLAIMER}

Portions of this document may be illegible in electronic image products. Images are produced from the best available original document. 


\section{CONTENTS}

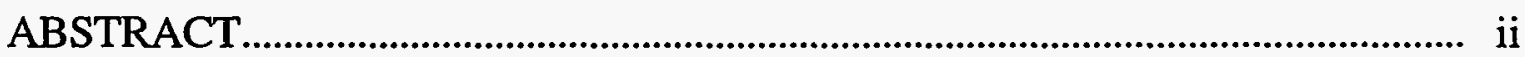

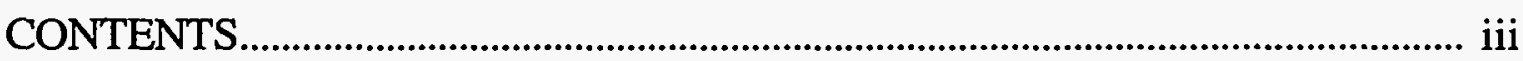

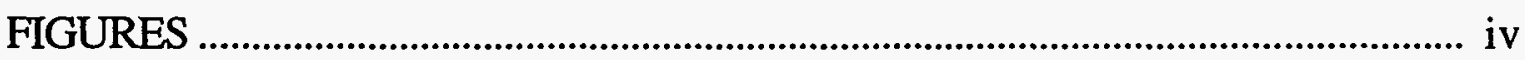

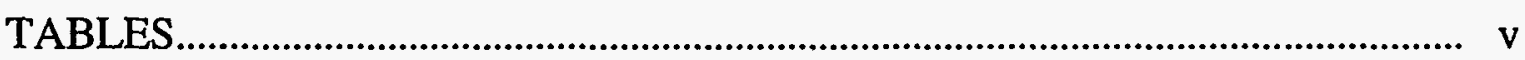

ACKNOWLEDGEMENT...................................................................................... v

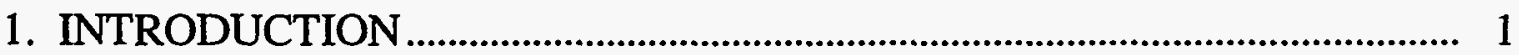

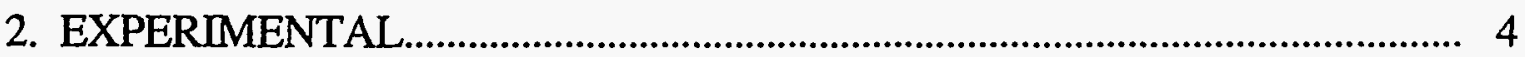

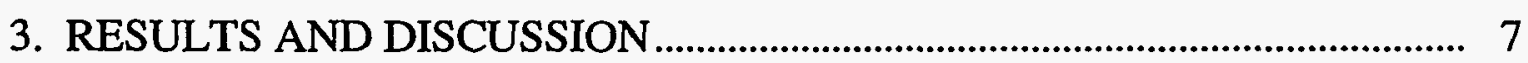

$3.1 \mathrm{CCl}_{4}$ Band Assignment ........................................................... 7

$3.2 \mathrm{CCl}_{4}$ Intensity Measurements...................................................1 1

$3.3 \mathrm{H}_{2}$ Intensity Measurements...............................................16

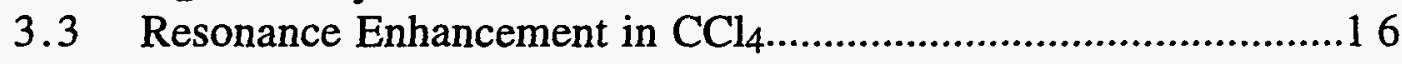

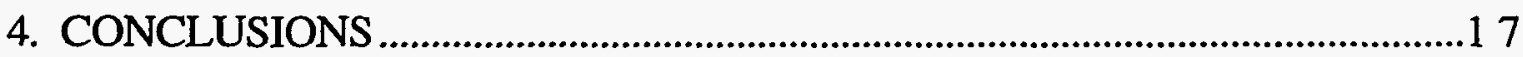

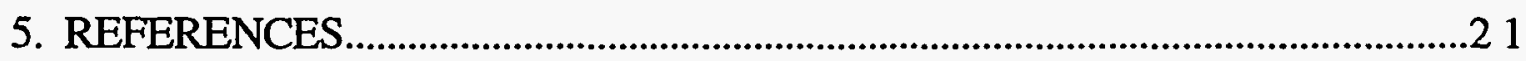




\section{FIGURES}

Figure 1.1 Relative intensities of Raman lines of $\mathrm{CCl}_{4}$ from

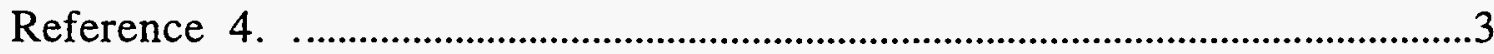

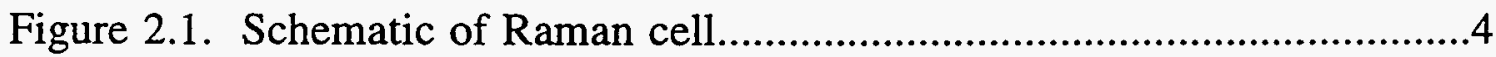

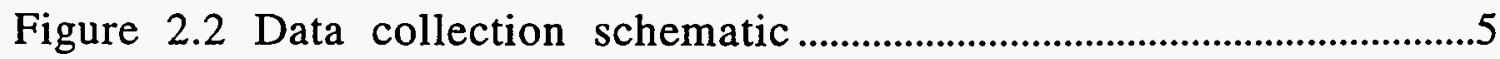

Figure 3.1. Raman spectrum of $\mathrm{CCl}_{4}$ with $\mathrm{KrF}$ laser excitation $(248 \mathrm{~nm})$

Figure 3.2. Molar extinction coefficient of vapor phase $\mathrm{CCl}_{4}$ as a function of frequency data taken from references 2 and 9.

Figure 3.3. Absorbance correction to incident and scattered radiation as a function of $\mathrm{CCl}_{4}$ pressure.

Figure 3.4. Plot of area of the $v_{1}$ band of $\mathrm{CCl}_{4}$ vs. pressure. .................14

Figure 3.5. Plot of area of the $v_{1}$ band of $\mathrm{CCl}_{4}$ vs. laser energy...........15

Figure 4.1. Sensitivity vs. range for $\mathrm{CCl}_{4}$ detection using the $v 1$ band. 


\section{TABLES}

Table 3.1. Results of curve fit of Rayleigh peak of hydrogen at 787 Torr..

Table 3.2. Results of curve fit of spectrum shown in Figure 3.1

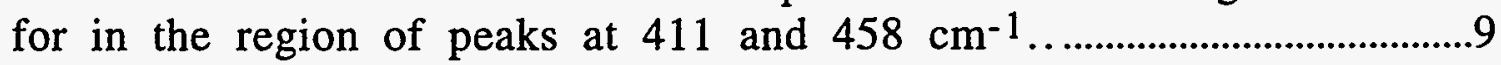

Table 3.3. Measured Raman frequencies of various potential

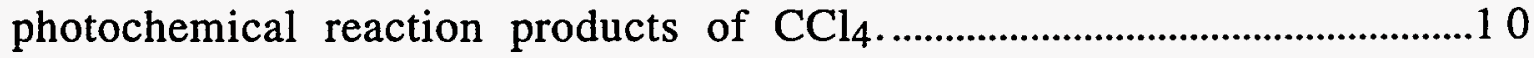




\section{ACKNOWLEDGEMENT}

This work was performed under the auspices of the U.S. Department of Energy. The authors would like to acknowledge the assistance of Dr. C. W. Brown at the Department of Chemistry of the University of Rhode Island for his comments on technical issues related to this work. 
Resonance Raman Spectroscopy of Volatile Organics - Carbon Tetrachloride

\section{INTRODUCTION}

Carbon tetrachloride $\left(\mathrm{CCl}_{4}\right)$ is one of a number of volatile organic chemicals (VOCs) of interest as pollutants which are regulated at very low levels (ppm to $\mathrm{ppb}$ ) by the EPA. Consequently, a need exists to measure these chemicals at these regulatory levels rapidly and, in many cases, in situ. Raman spectroscopy is one method which has the potential to be a useful tool for remote monitoring and has already found a number of applications for process and field monitoring of chemicals ${ }^{1}$. But while carbon tetrachloride has been detected using these remote sampling systems it is doubtful that the requisite sensitivity could be obtained using visible or near IR lasers. This is because of the relatively small cross section for the Raman effect. Under non-resonance conditions, the cross section increases according to a fourth power relationship to the frequency. Excitation using blue to ultraviolet radiation would be expected to increase the cross section and therefore the sensitivity. These gains are modest, however.

Large increases in the Raman cross section, have been observed when the excitation frequency is at or near an electronic absorption of the molecule. Resonance enhanced cross sections are many orders or magnitude $\left(10^{3}\right.$ to $\left.10^{6}\right)$ larger than their cross sections without such enhancement so that large gains in sensitivity might be expected. However such measurements are complicated by a potentially large florescence background as well a the need to use lasers in the UV region of the spectrum to access the electronic transitions of simple volatile organics.

For $\mathrm{CCl}_{4}$, the lowest energy electronic absorption is a dissociative state in which absorption results in the dissociation of the molecule ${ }^{2}$

$$
\mathrm{CCl}_{4} \rightarrow \mathrm{CCl}_{3}+\mathrm{Cl} \cdot
$$

This occurs in the UV below $260 \mathrm{~nm}$. Various attempts have been made to measure the resonance Raman spectrum of carbon tetrachloride in the liquid state. These measurements predate the availability of high-power, UV laser sources, however, and the 
excitation sources used were unable to approach the absorption maximum very closely. For example, Kaya et al.. ${ }^{3}$ report resonance enhancement of the asymmetric stretching mode of $\mathrm{CCl}_{4}$ in studies using a pulsed nitrogen laser at $337.1 \mathrm{~nm}$. An earlier, more complete study of the resonance Raman effect was performed by Buyken et al. ${ }^{4}$ using a mercury lamp as an excitation source. In this work, measurements were made on solutions of carbon tetrachloride in methanol using excitation sources from 435.8 to $253.7 \mathrm{~nm}$. Figure 1.1 shows the resonance enhancement for the various bands of $\mathrm{CCl}_{4}$.

Both the work of Buyken et al.. and Kaya et al. appear to indicate that the resonance enhancement in $\mathrm{CCl}_{4}$ is small and that the anti-symmetric stretching mode, $v_{3}\left(760-790 \mathrm{~cm}^{-1}\right)$, appears to show the largest enhancement. Enhancement of the symmetric stretch $v_{1}$ (459 $\left.\mathrm{cm}^{-1}\right)$ is surprisingly quite small. Yet, neither set of experiments are really very close to the absorption maximum of $\mathrm{CCl}_{4}$. Thus, it would appear that experiments closer to the absorption maximum might be in order to determine if the trends previously observed are maintained under true resonance conditions. Further, this is necessary to determine if resonance Raman could provide the basis for a probe to measure the in situ concentration of VOCs at levels of regulatory interest. To do this, we have chosen to make measurements of the the intensity of the $v_{1}$ mode of $\mathrm{CCl}_{4}$ in the gas phase using the Q-branch of $\mathrm{H}_{2}$ as a reference. Hydrogen was chosen since it does not have any electronic absorptions in the region of 248 nm. Further, Raman cross section data is available for both the Qbranch of hydrogen as well as the fundamentals of $\mathrm{CCl}_{4}$ which would enable a calculation of the resonance enhancement to be readily made. 


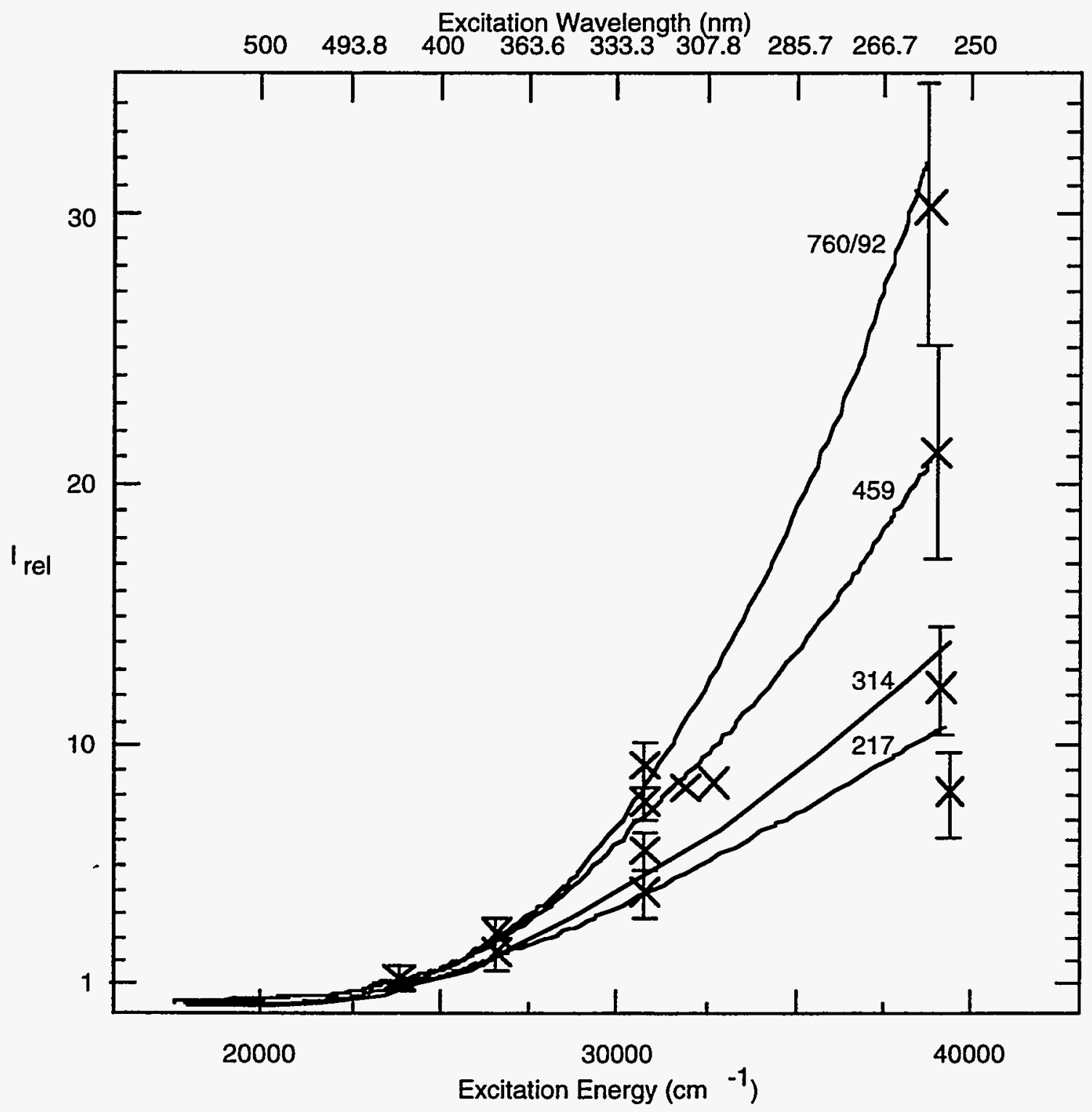

Figure 1.1 Relative intensities of Raman lines of $\mathrm{CCl}_{4}$ from Reference 4. Intensities normalized to $4358 \AA$ excitation. 


\section{EXPERIMENTAL}

The cell used for these experiments was fabricated from. rectangular quartz tubing nominally $1 \mathrm{~cm}$ by $0.5 \mathrm{~cm}$. The tubing was expanded to allow for a $3.2 \mathrm{~cm}$ diameter quartz window with a taper sufficient to allow for the focusing of the incident laser light. The incident laser beam was focus with a $50 \mathrm{~mm}$ focal length quartz lens placed next to this window. A 1/4" diameter Pyrex tube allowed the cell to be connected to a gas handling system for filling. A closed end tube allowed for condensation of liquid into the cell. This cell design allowed for minimal absorption of the scattered radiation while at the same time reducing optical damage to the window by the incident laser beam. A schematic of this cell is given in Figure 2.1.

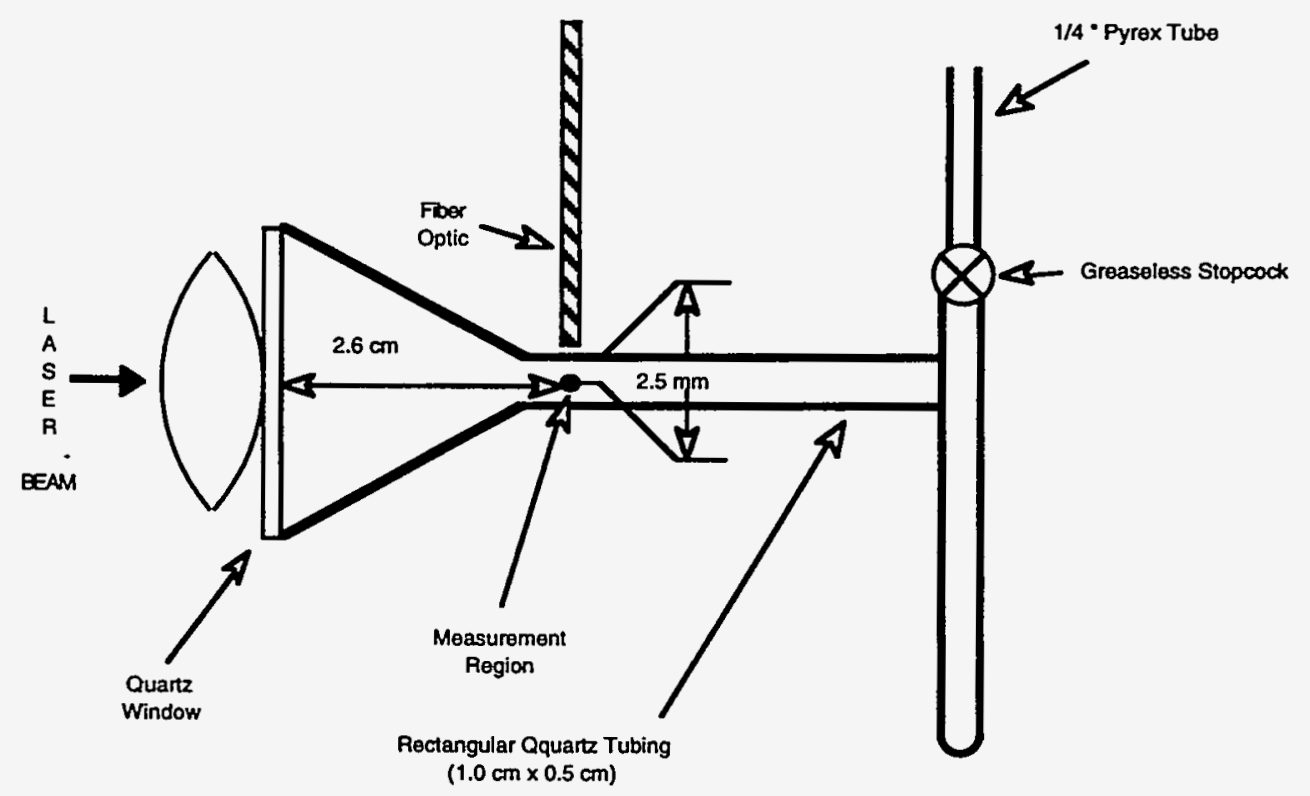

Figure 2.1. Schematic of Raman cell.

The laser used as an excitation source in these experiments was a Questex model 2220 excimer laser operating with a $\mathrm{KrF}$ gas fill and stable resonator optics. The laser energy was less than $400 \mathrm{~mJ} / \mathrm{pulse}$ and the repetition rate was controlled by the data collection system (see below).

Scattered radiation was focused onto a quartz optical fiber coupled to a $1.5 \mathrm{~m}$ SPEX spectrometer. The detector was a blueintensified 1024 channel solid state detector (EG\&G PARC Model 1421) which was thermoelectrically cooled to $-15^{\circ} \mathrm{C}$. The entire 
experiment was controlled using an EG\&G Model 1461 optical multichannel analyzer (OMA). The OMA was operated in the data acquisition (DA) mode 5 with a total exposure time of 16.634 ms/scan. The laser was triggered with a pulse from the EG\&G Model 1463 scan control at $\mathrm{T}_{0}$. This pulse also triggered the OMA's 1303 Gate pulse interface. After an appropriate delay to allow for the laser to fire, $\Delta \mathrm{T}_{1}$, in the range of $1 \mu \mathrm{s}$, the detector was opened using a gate width of $\Delta \mathrm{T}_{2}$ and data collected. For multiple scans a delay between laser firings of approximately 1 second was used by adjusting the number of scans ignored in DA mode 5 to 59 . The delay and gate width were experimental parameters which were varied to optimize the Raman signal as well as minimize the florescence background. A schematic for this process is shown in Figure 2.2. Data was analyzed using integration and band fitting routines contained in Grams $/ 386^{\mathrm{TM}}$.

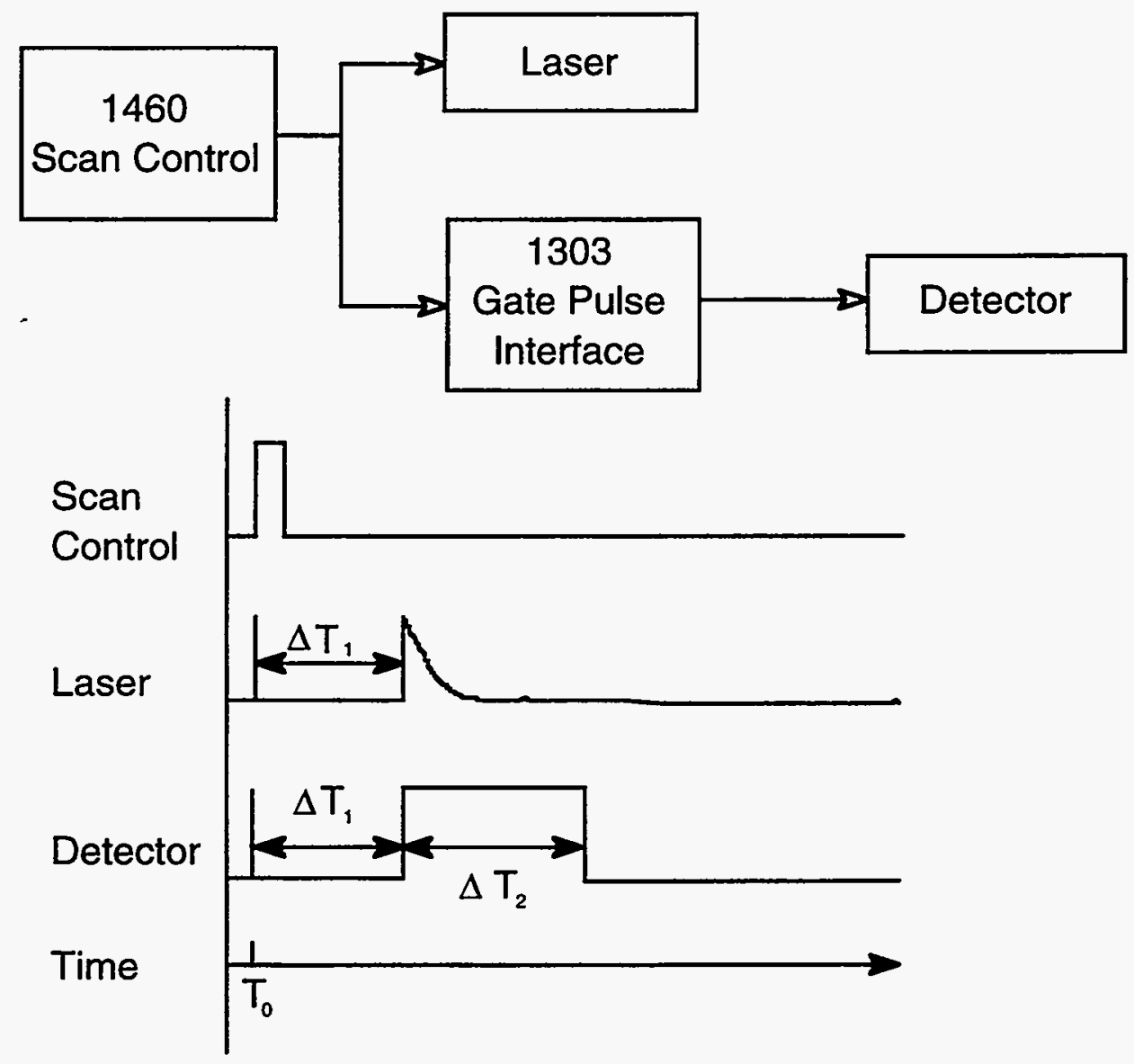

Figure 2.2 Data collection schematic 
The carbon tetrachloride used in these tests was Mallincrodt AR grade (lot umber 4368KXHK-R). The material was further purified by cryodistillation into a glass bulb. Dissolved gases were removed using several freeze-pump-thaw cycles and the purified liquid stored under reduced pressure. For experiments in which equilibrium vapor pressure was desired, a small sample was cryodistilled into the Raman cell. The hydrogen used in these experiments was medium purity gas $(99.99 \%)$. For all gas phase experiments except for those conducted with $\mathrm{CCl}_{4}$ at equilibrium vapor pressure, the cell was filled while monitoring the pressure using a capacitance manometer. 


\section{RESULTS AND DISCUSSION}

\section{1 $\mathrm{CCl}_{4}$ Band Assignment}

Irradiation of $\mathrm{CCl}_{4}$ with excimer laser radiation at $248 \mathrm{~nm}$ resulted in decomposition of the vapor at high repetition rates. The decomposition produced a fine particulate in the cell which precluded making accurate band intensity measurements and, in the more extreme cases, obscured the Raman signal entirely. To minimize the effects of photodecomposition, data was taken using a single or in some cases two laser pulses. For measurements of hydrogen and nitrogen, no particulate was formed so multiple scans involving many laser pulses were taken. In addition to photodecomposition, a fluorescence background was also observed. In order to minimize this background, the detector gate width was kept small in the $\mathrm{CCl}_{4}$ experiments. The typical experimental timing for a measurement was a value for $\Delta \mathrm{T}_{1}$ of $1500 \mathrm{~ns}$ and $\Delta \mathrm{T}_{2}$ of $200 \mathrm{~ns}$ (see Figure 2.2). This allowed sufficient time for both the Rayleigh and Raman peaks to be observed. A typical Raman spectrum of $\mathrm{CCl}_{4}$ is shown in Figure 3.1. Peaks were observed at a Raman shift of $411 \pm$ $2,457 \pm 2,712 \pm 4$ and $820 \pm 13 \mathrm{~cm}^{-1}$. The 820 peak is quite broad and appears to be a doublet with maxima at roughly $806 \pm 8$ and 837 $\pm 11 \mathrm{~cm}^{-1}$. Since each diode element in the detector was approximately $2 \mathrm{~cm}^{-1}$ in the region of the $248 \mathrm{~nm}$ excitation, it is reasonable to assume that the band frequencies are accurate to \pm 5 $\mathrm{cm}^{-1}$. In addition, the error in calibration appears to be $6-7 \mathrm{~cm}^{-1}$.

The assignment of the 457 band is quite straightforward. Its frequency corresponds well to that of the symmetric stretch $v_{1}$ of $\mathrm{CCl}_{4}\left(459 \mathrm{~cm}^{-1}\right)$. None of the remaining fundamentals of $\mathrm{CCl}_{4}$ appear to be evident in any of the spectra taken. Several possibilities were considered for the assignment of the remaining three bands. One possibility is that other excitation lines from the laser are giving rise to some of the spectral features. Thus, the band at $411 \mathrm{~cm}^{-1}$ could be assigned to $v_{1}$ if an excitation source existed at $46 \mathrm{~cm}^{-1}$ to the blue of the $248 \mathrm{~nm}$ laser line. This was investigated by trying to fit the Rayleigh peak produced by a single pulse at $248 \mathrm{~nm}(330 \mathrm{~mJ})$ irradiating the Raman cell which was filled with 787 Torr of hydrogen with either a single Gaussian peak or with a pair of Gaussians. In the case of the two Gaussian peaks, the frequency of one peak was fixed to a $\Delta \mathrm{cm}^{-1}$ of $46 \mathrm{~cm}^{-1}$. The results of this 
analysis are given in Table 3.1. It can be seen that the two Gaussian peaks give a better fit to the spectrum.

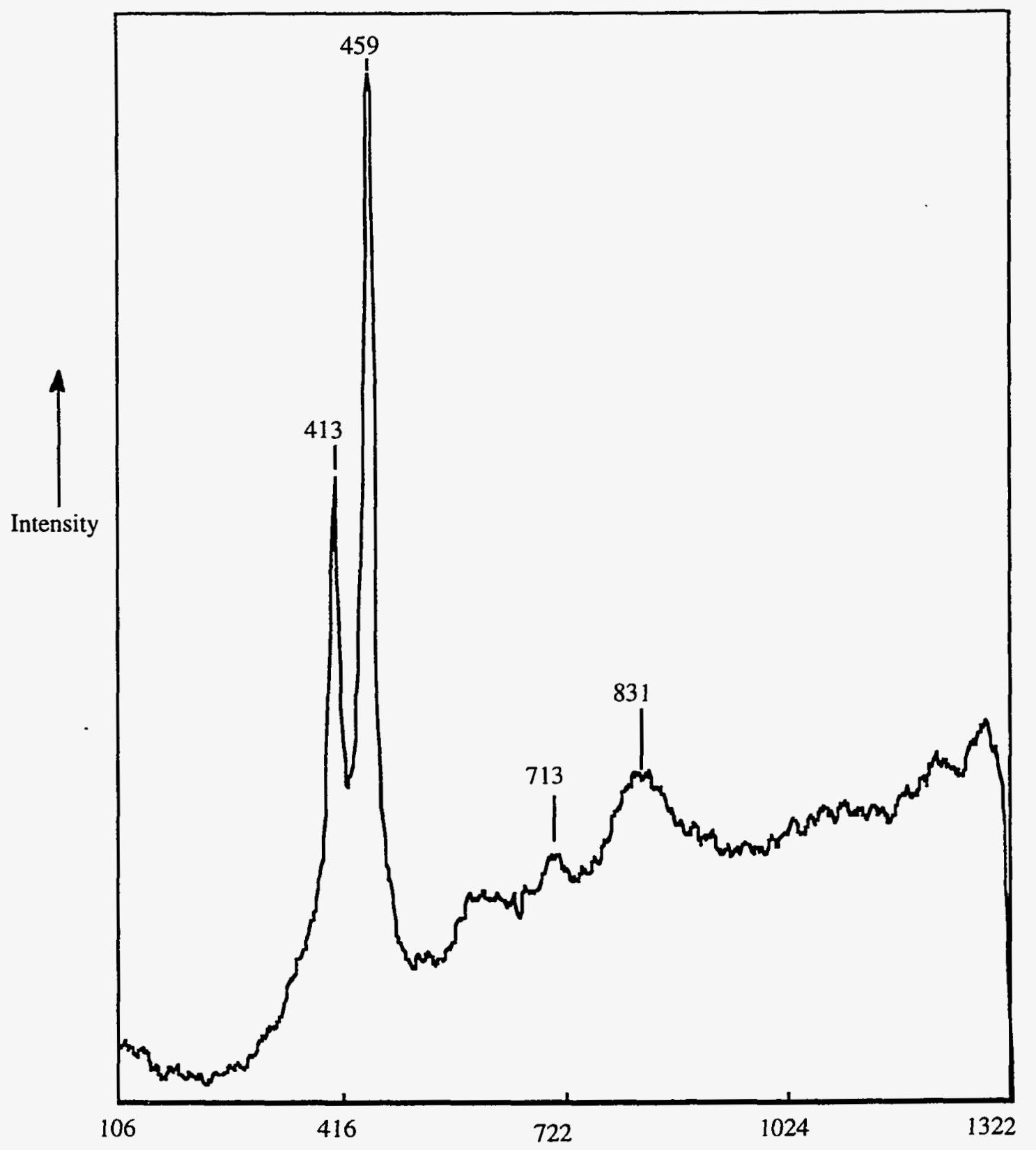

Figure 3.1. Raman spectrum of $\mathrm{CCl}_{4}$ with $\mathrm{KrF}$ laser excitation $(248 \mathrm{~nm})$. The $\mathrm{CCl}_{4}$ pressure was 66 Torr and the laser energy was $68 \mathrm{~mJ}$. The data was taken with a single laser pulse. 
Table 3.1. Results of curve fit of Rayleigh peak of hydrogen at 787 Torr. A linear baseline was assumed and the data fitted with either a single Gaussian (Case 1) or two Gaussian peaks (Case 2). In Case 2 the first peak was fixed to a frequency shift of $46 \mathrm{~cm}^{-1}$.

\begin{tabular}{|c|c|c|}
\hline $\begin{array}{l}\text { Peak } \\
\left(\mathrm{cm}^{-1}\right)\end{array}$ & Height & $\begin{array}{l}\text { Width } \\
\left(\mathrm{cm}^{-1}\right)\end{array}$ \\
\hline $\begin{array}{l}\text { Case } 1 \\
\begin{array}{l}-9.87 \pm 0.001 \\
\text { Baseline } \\
\text { Correlation } \\
\left(\mathrm{R}^{2}\right)=0.997\end{array}\end{array}$ & $\begin{array}{l}10249.07 \pm 0.40 \\
\text { Slope }=46.6 \pm 0.1\end{array}$ & $\begin{array}{c}57.94 \pm 0.003 \\
\text { Intercept }=-0.145 \pm 0.001\end{array}$ \\
\hline 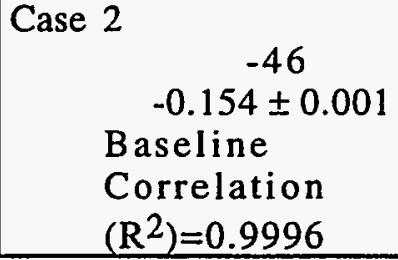 & $\begin{array}{c}954.3 \pm 0.70 \\
10322.9 \pm 0.50 \\
\text { Slope }=19.8 \pm 0.1\end{array}$ & $\begin{array}{c}47.09 \pm 0.03 \\
54.231 \pm 0.003 \\
\text { Intercept }=0.0097 \pm 0.0009\end{array}$ \\
\hline
\end{tabular}

This data may be compared with parameters obtained from fitting the intensity data in the region of the two bands at 411 and $457 \mathrm{~cm}^{-1}$. When the data for this region of the spectrum shown in Figure 3.1 was fit using a sum of Gaussians, it was found that the two peaks had the parameters shown in Table 3.2. It can be seen from a comparison of the data in the two tables that the peaks at 411 and $457 \mathrm{~cm}^{-1}$ are much narrower than the corresponding peaks at the excitation wavelengths. Further, the ratio of the areas of the 457 and $.411 \mathrm{~cm}^{-1}$ peaks is 2 , while the ratio of the areas of the -0.2 and -46 $\mathrm{cm}^{-1}$ excitation lines is 12 . This latter difference could be explained by differences in the cross section at the different excitation frequencies.

Table 3.2. Results of curve fit of spectrum shown in Figure 3.1 in the region of peaks at 411 and $458 \mathrm{~cm}^{-1}$. A linear baseline was assumed and the data fitted with four Gaussian peaks (Case 2).

\begin{tabular}{|c|c|c||}
\hline $\begin{array}{c}\text { Peak } \\
\left(\mathrm{cm}^{-1}\right)\end{array}$ & Height & $\begin{array}{c}\text { Width } \\
\left(\mathrm{cm}^{-1}\right)\end{array}$ \\
\hline $411.24 \pm 0.08$ & $189 \pm 2$ & $22.9 \pm 0.2$ \\
$398 . \pm 2$ & $41 \pm 1$ & $94 \pm 5$ \\
$457.53 \pm 0.03$ & $418 \pm 2$ & $21.9 \pm 0.1$ \\
$49.3 \pm 0.3$ & $25 \pm 1$ & $13.3 \pm 0.8$ \\
Baseline & Slope $=116 \pm 5$ & Intercept $=0.10 \pm 0.01$ \\
Correlation $\left(\mathrm{R}^{2}\right)=0.998$ & & \\
\hline
\end{tabular}


The other possibility is that the additional bands observed in the spectrum are due to chemical species present as impurities or chemical reactions. Since the $\mathrm{CCl}_{4}$ used was research grade and was further purified by cryodistillation any impurities should be at the trace level. Among the products of photochemical reaction are $\mathrm{CCl}_{3}$, $\mathrm{Cl}_{2}, \mathrm{C}_{2} \mathrm{Cl}_{4}$, and $\mathrm{C}_{2} \mathrm{Cl}_{6}$. Of these chemicals only the trichloromethyl radical is unstable. The Raman spectrum for each of these compounds has been measured and the appropriate frequencies are listed in Table 3.3. It can be readily seen from this table that none of the frequencies coincide with the peaks seen at $411 \pm 2,712 \pm 4$ and $820 \pm 13 \mathrm{~cm}^{-1}$. (The $837 \pm 11 \mathrm{~cm}^{-1}$ portion of the doublet can be rejected on relative intensity considerations.)

Table 3.3. Measured Raman frequencies of various potential photochemical reaction products of $\mathrm{CCl}_{4}$.

\begin{tabular}{||c|c|c|l||}
\hline Compound & $\begin{array}{c}\text { Raman Shift } \\
\left(\mathrm{cm}^{-1}\right)\end{array}$ & Assignment & Reference \\
\hline $\mathrm{CCl}_{3} \cdot$ & 264 & $v_{3}$ & Hase et al.5 \\
& 363 & $v_{2}$ & \\
& 482 & & \\
$\mathrm{Cl}_{2} \cdot$ & 569 & $v_{1}$ & Herzberg6 \\
$\mathrm{C}_{2} \mathrm{Cl}_{4}$ & 236 & & Herzberg7 \\
& 347 & $v_{3}$ & \\
& 447 & $v_{6}$ & \\
$\mathrm{C}_{2} \mathrm{Cl}_{6}$ & 512 & $v_{2}$ & \\
& 162 & & Hamilton and Cleveland 8 \\
& 223 & & \\
& 340 & & \\
& 431 & & \\
& 959 & & \\
& 975 & & \\
\hline
\end{tabular}

Based upon the above considerations, only the assignment of the $459 \mathrm{~cm}^{-1}$ band can be made with any confidence. Even for this band, the narrowness of the bandwidth is troublesome. Some of the uncertainty could no doubt be removed by using a narrower excitation source. This could be done by narrowing the $\mathrm{KrF}$ laser emission using an etalon or by using another excitation source. 
Neither of these approaches could be taken however because they were both beyond the scope of the current work. For the purposes of determining resonance enhancement, an unambiguous assignment of all spectral features is not necessary. The intensity of the $459 \mathrm{~cm}^{-1}$ band can be easily measured in spectra and from this intensity it is possible to calculate the resonance enhancement as will be seen below.

\section{$3.2 \mathrm{CCl}_{4}$ Intensity Measurements}

Irradiation of $\mathrm{CCl}_{4}$ with excimer laser radiation at $248 \mathrm{~nm}$ resulted in decomposition of the vapor at high repetition rates and high laser energies. The decomposition produced a fine particulate in the cell which precluded making accurate band intensity measurements and, in the more extreme cases, obscured the Raman signal entirely. To minimize the effects of photodecomposition, data was taken using a single or in some cases two laser pulses. Under these experimental conditions, the $v_{1}$ band was easily observed.

Because the experiments involved excitation with radiation which overlaps with the UV absorption spectrum of the molecule, correction had to be made for the amount of radiation reaching the scattering area as well as for the absorption of the Raman scattered radiation by gas between the scattering center and the collection optics. The amount of light absorbed of course depends upon the molar extinction coefficient at the frequency of interest and the path length. For $\mathrm{CCl}_{4}$, there have been two measurements of the molar extinction coefficient in the gas phase as a function of frequency by Lacher et al. 2 and by Gordus and Bernstein. ${ }^{\text {The results of these }}$ measurements are given in Figure 3.2. In the region of $\mathrm{KrF}$ excitation $\left(40,248 \mathrm{~cm}^{-1}\right)$, there is very little difference between the two measurements. Using the values of Gordus and Bernstein, the appropriate correction and the cell geometry to the incident and scattered radiation can be made. The results of this are shown as a function of $\mathrm{CCl}_{4}$ pressure in Figure 3.3. It can be seen from this figure that the incident radiation has a correction factor of 1.5 to 15 $\%$ over the pressure range studied, while the correction at the frequency of the Raman scattered radiation amounts to $1 \%$ or less. This difference is due mainly to the nearly order of magnitude difference in the path length between the incident and scattered radiation. The absorption of the Raman scattered light was ignored because it was small compared experimental variation in the laser energy as well as uncertainties in the estimate of band areas. 


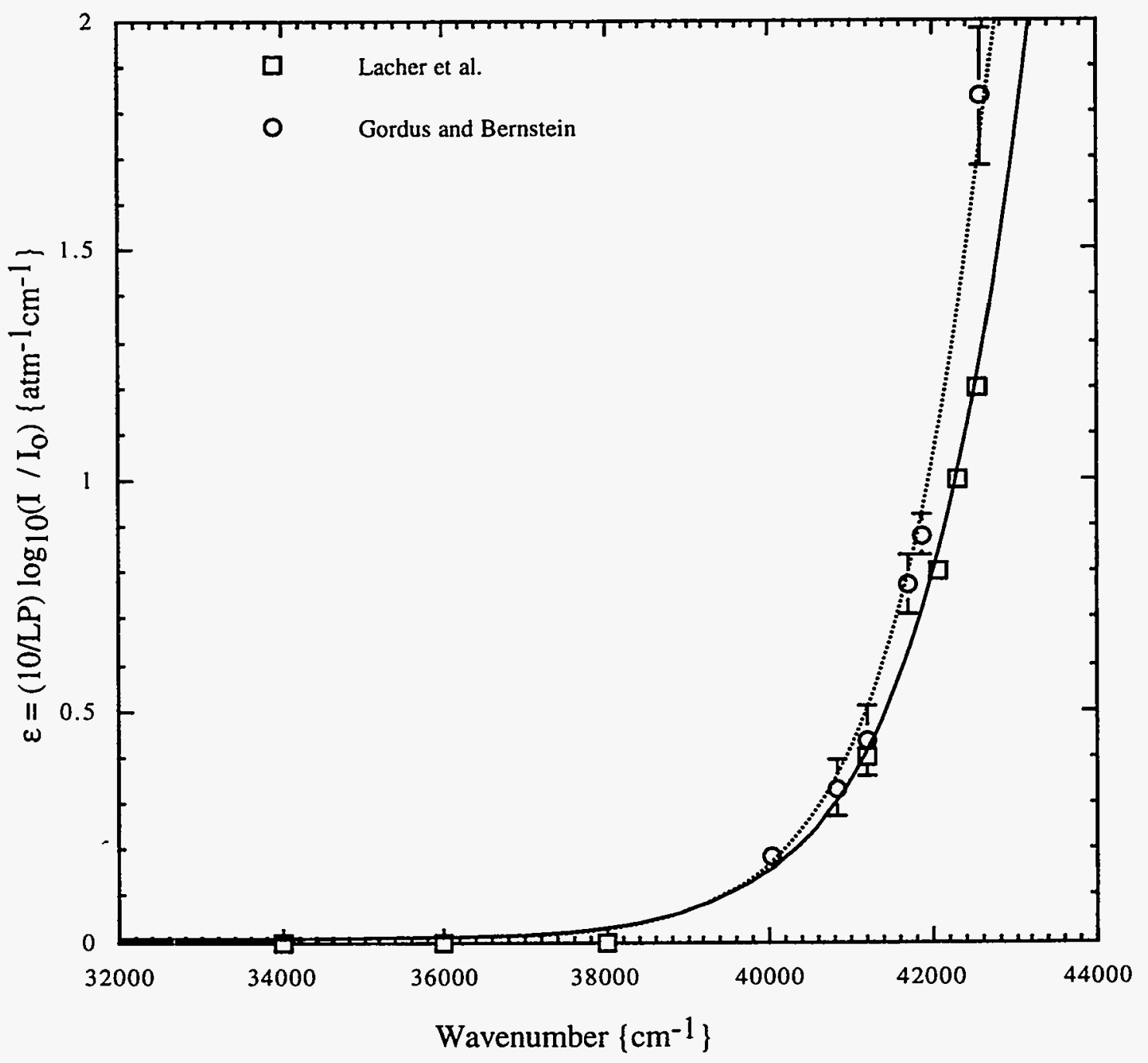

Figure 3.2. Molar extinction coefficient of vapor phase $\mathrm{CCl}_{4}$ as a function of frequency (data taken from References 2 and 9). 


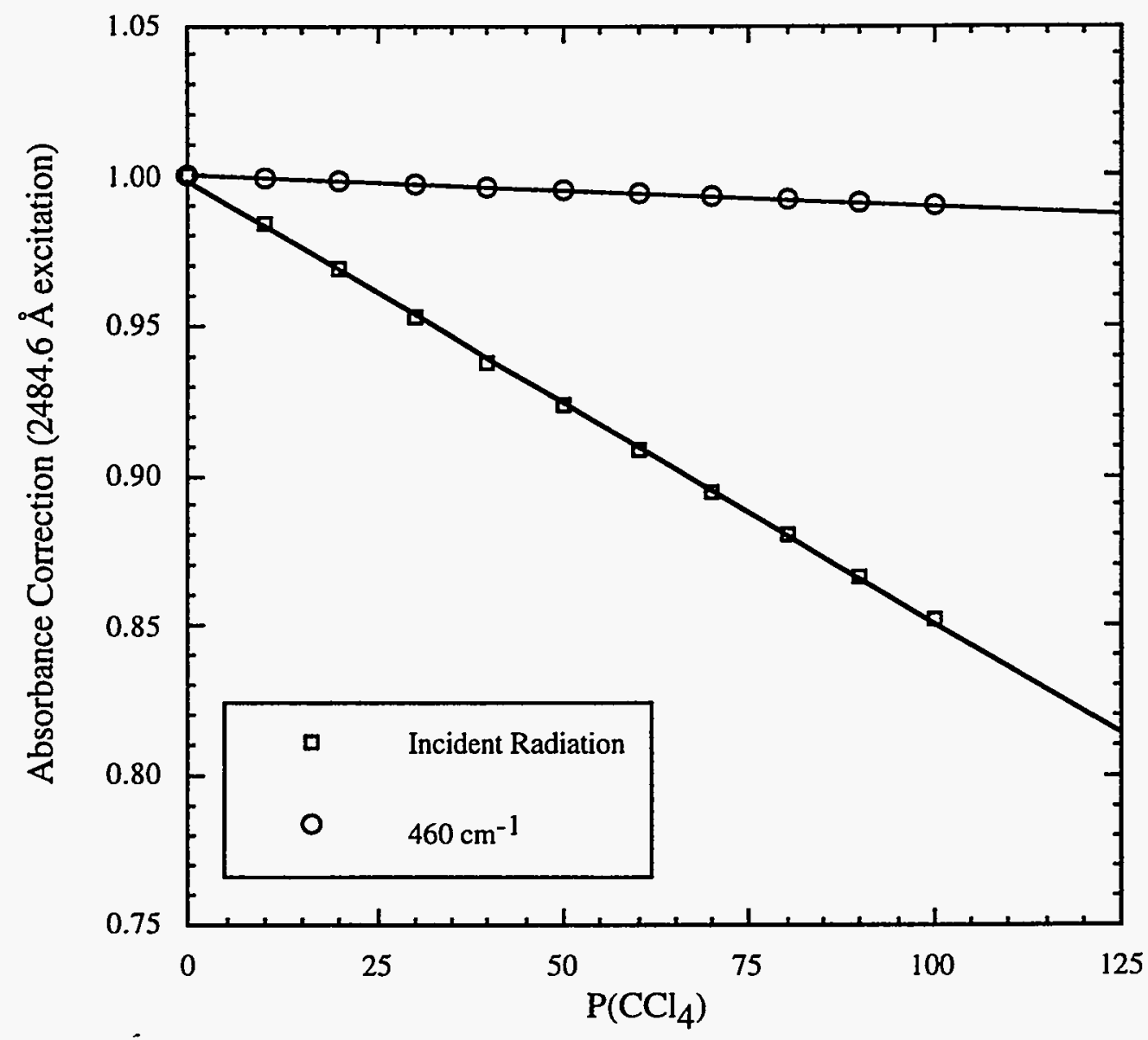

Figure 3.3. Absorbance correction to incident and scattered radiation as a function of $\mathrm{CCl}_{4}$ pressure. Data calculated from extinction coefficient measurements from Reference 9 and from the cell geometry used. The incident radiation was assumed to be at $40250 \mathrm{~cm}^{-1}$ $(248.6 \mathrm{~nm})$ and the scattered radiation corresponds to the $v_{1}$ band Raman of $\mathrm{CCl}_{4}$ red shifted from the $\mathrm{KrF}$ excitation by $460 \mathrm{~cm}^{-1}$.

In addition to an absorption correction, intensity data were normalized to account for differences in gas pressure, laser energy and exposure time between the $\mathrm{CCl}_{4}$ and the reference gas (hydrogen). The Raman intensity is proportional to the incident light intensity as well as the number of scattering molecules. Given the possibility for multiphoton effects, this dependence was verified for the measurements of the $v_{1}$ band intensity (Figures 3.4 and 3.5). Based upon these experiments, the intensity for the $v_{1}$ band of $\mathrm{CCl}_{4}$, 
had an average value of $3.4 \pm 1.6$ counts $\cdot \mathrm{mJ}^{-1} \cdot \mathrm{Torr}^{-1}$ under the particular experimental conditions used.

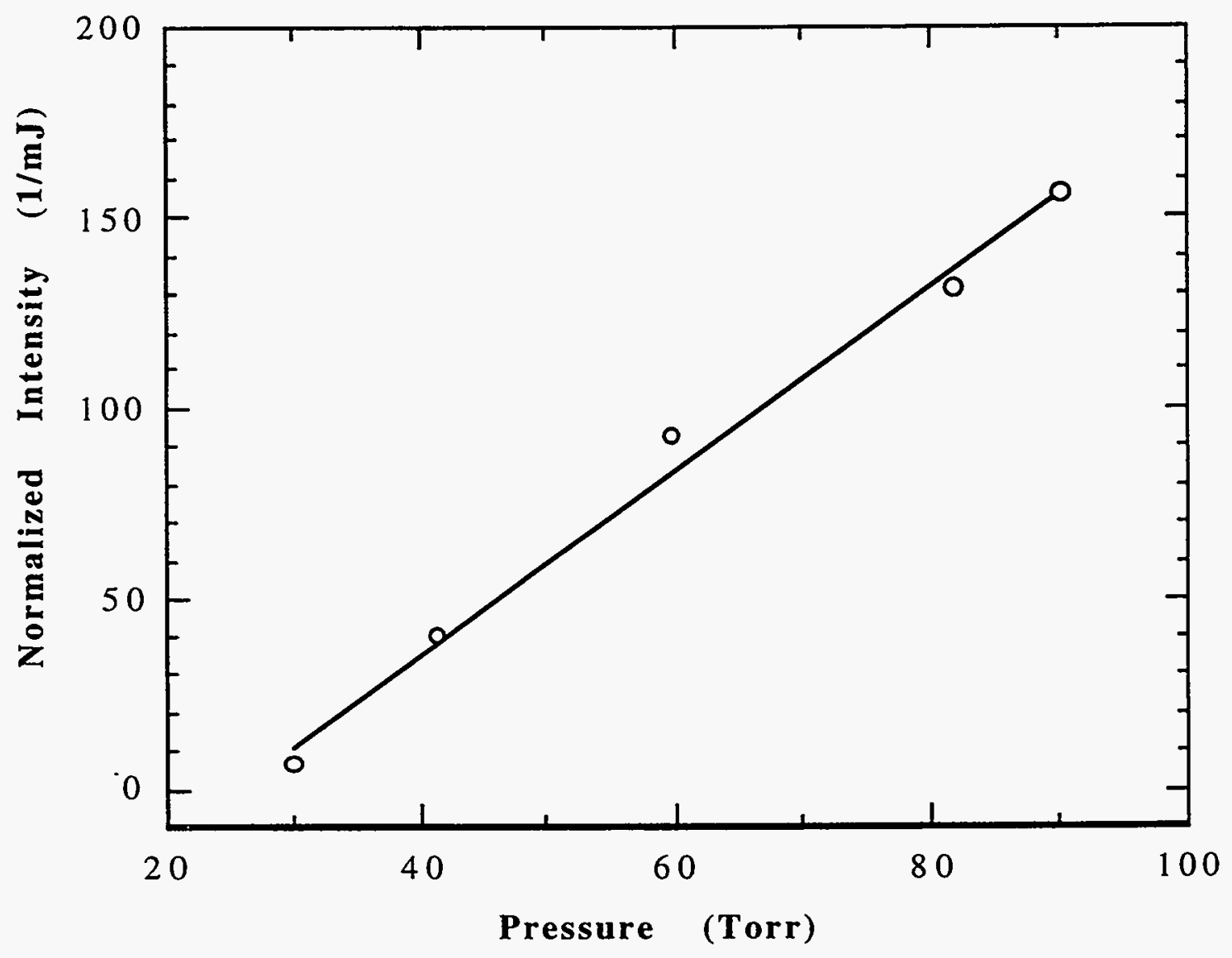

Figure 3.4. Plot of area of the $v_{1}$ band of $\mathrm{CCl}_{4}$ vs. pressure. The area was normalized by dividing by the laser energy which was corrected for absorption by the $\mathrm{CCl}_{4}$. The laser energy was varied from 315 to $360 \mathrm{~mJ} / \mathrm{pulse}$. The data represents the signal obtained from two laser pulses. 


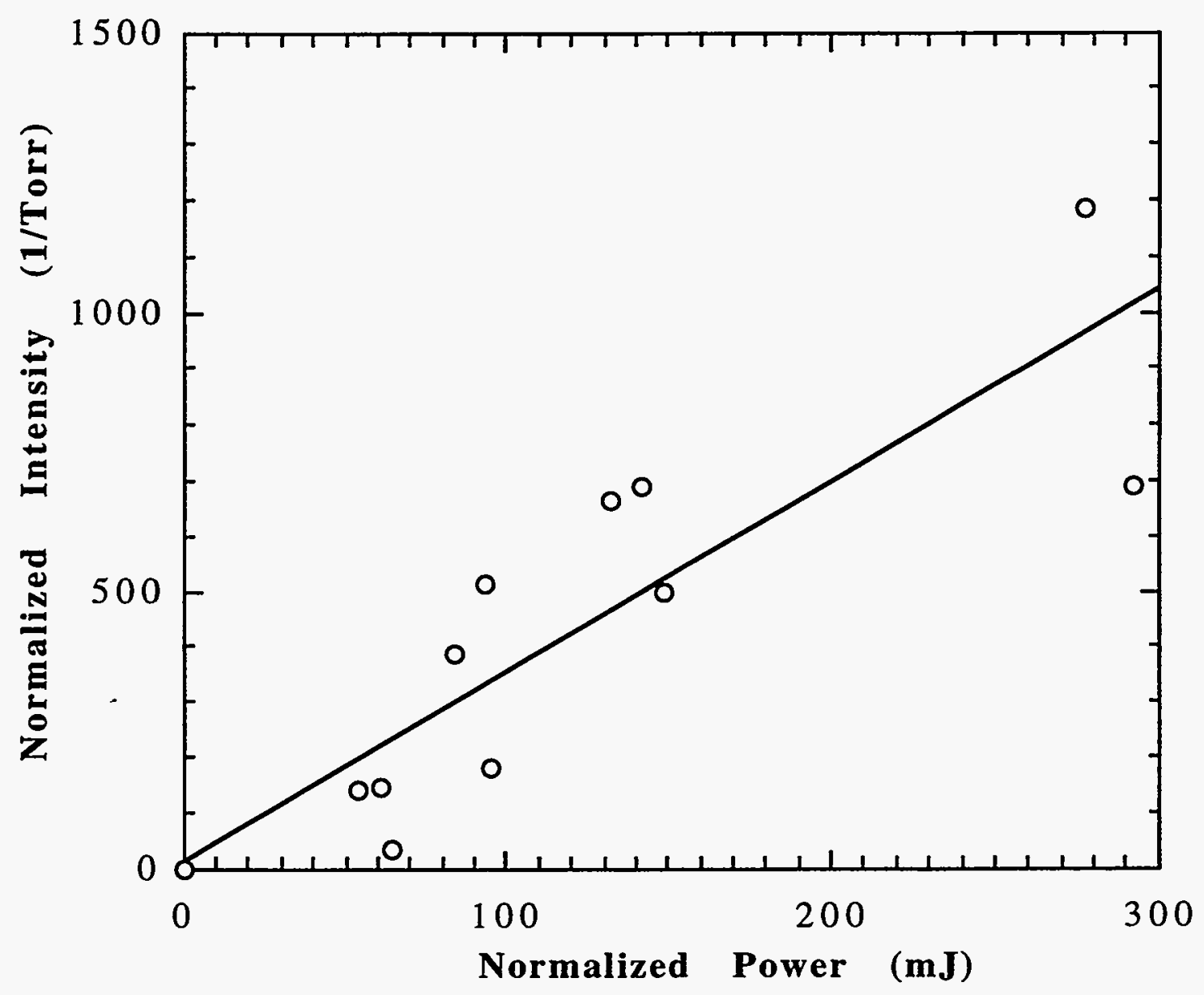

Figure 3.5. Plot of area of the $v_{1}$ band of $\mathrm{CCl}_{4}$ vs. laser energy. The area was normalized by dividing by the gas pressure and the laser energy was corrected for absorption by the $\mathrm{CCl}_{4}$. The laser energy varied between 55 to $280 \mathrm{~mJ} / \mathrm{pulse}$. The data represents the signal obtained from a single laser pulse. 


\section{3 $\mathrm{H}_{2}$ Intensity Measurements}

For hydrogen, it was necessary to accumulate data over a long period of time (500 scans) at an elevated pressure relative to the $\mathrm{CCl}_{4}$ in order to obtain sufficient intensity in the region of the Qbranch $(\Delta \mathrm{cm}-1=4160)$. Care was taken to obtain this data under identical optical conditions. This meant using the same gas cell as well as keeping the same alignment of other optical components. Thus, the quartz cell used limited the pressure to slightly above atmospheric ( 790 Torr). Since the hydrogen has no electronic transitions which overlap the laser frequency an absorbance correction was not made. The normalized intensity measured for the $\mathrm{H}_{2}$ Q-branch under these conditions was $8.2 \times 10^{-5}$ counts $\cdot \mathrm{mJ}^{-1}$ - Torr $^{-1}$.

\subsection{Resonance Enhancement in $\mathrm{CCl}_{4}$}

The ratio of the two normalized intensities for the $v_{1}$ band of $\mathrm{CCl}_{4}$ and the Q-branch of $\mathrm{H}_{2}$ was $4.1 \pm 1.9 \times 10^{4}$. Since the instrumental parameters for the data collection were the same, this should be the ratio of the Raman cross sections. In order to calculate the resonance enhancement, this value can be compared with the literature values for the ratio of the normalized Raman cross sections measured at frequencies away from the $\mathrm{CCl}_{4} \mathrm{UV}$ absorption. Using data tabulated by Schrötter and Klöckner ${ }^{10}$, the ratio of the normalized differential Raman scattering cross sections for the $v_{1}$ band of $\mathrm{CCl}_{4}$ to the Q-branch of $\mathrm{H}_{2}$ was $1.8 \pm 0.2$ over a range of excitation wavelengths from 337 to $515 \mathrm{~nm}$. Based upon this data, the resonance enhancement of $v_{1}$ band of $\mathrm{CCl}_{4}$ at $248 \mathrm{~nm}$ is $2.3 \pm 1.1$ $x 10^{4}$. This value is consistent with typical resonance enhancements observed for other species. 


\section{CONCLUSIONS}

This study raises some problems in the complete assignment of the bands obtained when carbon tetrachloride is irradiated with a laser which overlaps its electronic absorption band. Complete assignment of the observed bands was not possible within the scope of the current effort. Clearly, however, resonance enhancement of the $v_{1}$ band was observed. This enhancement of the symmetric stretching mode is consistent with the excited state geometry in which the carbon-chlorine bonds lengthen. ${ }^{3}$ The magnitude of the resonance enhancement of the $v_{1}$ band measured in these studies is roughly 3 orders of magnitude higher than that measured by Buken et al. ${ }^{4}$ However, it is more typical of that observed for the resonance enhancement of other molecular species. Thus, despite the fact that the excited state is dissociative, it should be possible to exploit the resonance enhancement to develop an analytical method to detect trace quantities of $\mathrm{CCl}_{4}$ in either the vapor phase or dissolved in either an aqueous or non aqueous liquid.

The potential sensitivity of such a method has been documented in a review by Vickers et $\mathrm{al}^{11}$ in which detection of organics in the range of low ppb or sub-micromolar range is claimed. Our studies on carbon tetrachloride indicate that a signal of thousands of counts above background can be measured in a single laser pulse at gas pressures $<100$ Torr and laser energies on the order of a few hundred mJ. This implies a detection limit of $<<600$ $\mu$ molar. It must be stressed that the optical system used in these experiments was not optimized for trace detection. A further point to consider in this regard is that the excitation wavelength used $(248 \mathrm{~nm})$ is not at the $\mathrm{CCl}_{4}$ absorption maximum. Comparison of our results with those measured using excitation wavelengths further from resonance imply large sensitivity gains can be made by adjusting the excitation source closer to the absorption maximum.

A crucial parameter in the design of any instrumentation for field masurement of VOCs using Raman spectroscopy is the Raman cross section, $\frac{\delta \sigma}{\delta \Omega}$. This cross section is easily calculated from the the resonance enhancement measured for the $v_{1}$ band of $\mathrm{CCl}_{4}$ at $248 \mathrm{~nm}$ in the current study and cross section data given in Reference 10. The value obtained is $1 \times 10^{-25} \mathrm{~cm}^{2} / \mathrm{sr}$. Using this value, one can 
estimate the sensitivity for both remote detection of $\mathrm{CCl} 4$ as well as in situ measurements.

For remote detection in the gas phase, one can use the approach suggested by Barletta ${ }^{12}$. The experimental cross section derived above is the same cross section assumed by Barletta in his assessment. Hence, the results of his calculations for 248 excitation as well as his conclusions are directly applicable to to the detection of $\mathrm{CCl}_{4}$ remotely via a Raman lidar system. The calculations indicate that sub-ppm sensitivity can be achieved over short ranges, i.e., $<0.5$ $\mathrm{km}$ as seen in Figure 4.1 .

For liquids, one might expect a slight increase in the cross section due to the internal field effect. For neat liquid $\mathrm{CCl}_{4}$ this increase has been measured and is reported by Schrötter and Klöckner to be $3.5 \pm 0.5 .10$ Thus, for a system designed to detect VOCs as either liquid contamination on surfaces or in solution, gas phase cross sections provide a conservative estimate of the sensitivity. Eckbreth ${ }^{13}$ defines the fractional Raman yield, YRaman, as

$$
\mathrm{Y}_{\mathrm{Raman}},=\mathrm{n} \frac{\delta \sigma}{\delta \Omega} \Omega \mathrm{L} \varepsilon
$$

where.

and

$$
\begin{aligned}
& \mathrm{n}=\text { number density } \\
& \Omega=\text { scattering solid angle } \\
& \mathrm{L}=\text { sampling extent }
\end{aligned}
$$

$\varepsilon=$ collection efficiency

Using the above equation and the derived gas phase cross section of $10^{-25} \mathrm{~cm}^{2} / \mathrm{sr}$ from this study, one can compute the anticipated sensitivity for an in situ system. To do this we have assumed reasonable values for the scattering angle of $3.1 \times 10^{-2} \mathrm{sr}$ ( $\mathrm{f \# 5}$ collection optics) and sampling extent, $1 \mathrm{~mm}$, as well as a collection efficiency of $30 \%$. For $1 \mathrm{ppm}$ of $\mathrm{CCl}_{4}, \mathrm{Y}_{\mathrm{Raman}}$ is $3.6 \times 10^{-13}$. At $248 \mathrm{~nm}$, one pulse at $300 \mathrm{~mJ} /$ pulse has $3.8 \times 10^{17}$ photons. This means $1.4 \times 10^{5}$ photons would be produced as a Raman signal spread out over the band width. For a detector with a quantum efficiency of $20 \%$ and a bandwidth (FWHM) of $22 \mathrm{~cm}^{-1}$, there should be approximately 2400 counts in a $2 \mathrm{~cm}^{-1}$ increment centered at the band maximum. One should therefore be able to detect $1 \mathrm{ppm}$ of $\mathrm{CCl}_{4}$ in a single laser pulse with a signal to noise $(\mathrm{S} / \mathrm{N})$ of about 50. 
For a $\mathrm{S} / \mathrm{N}$ of 10 , one could detect $\sim 40 \mathrm{ppb}$. Increases in the cross section due to the internal field effect as well as summing the data from multiple laser pulses would result in a proportional lowering of the detection limit.

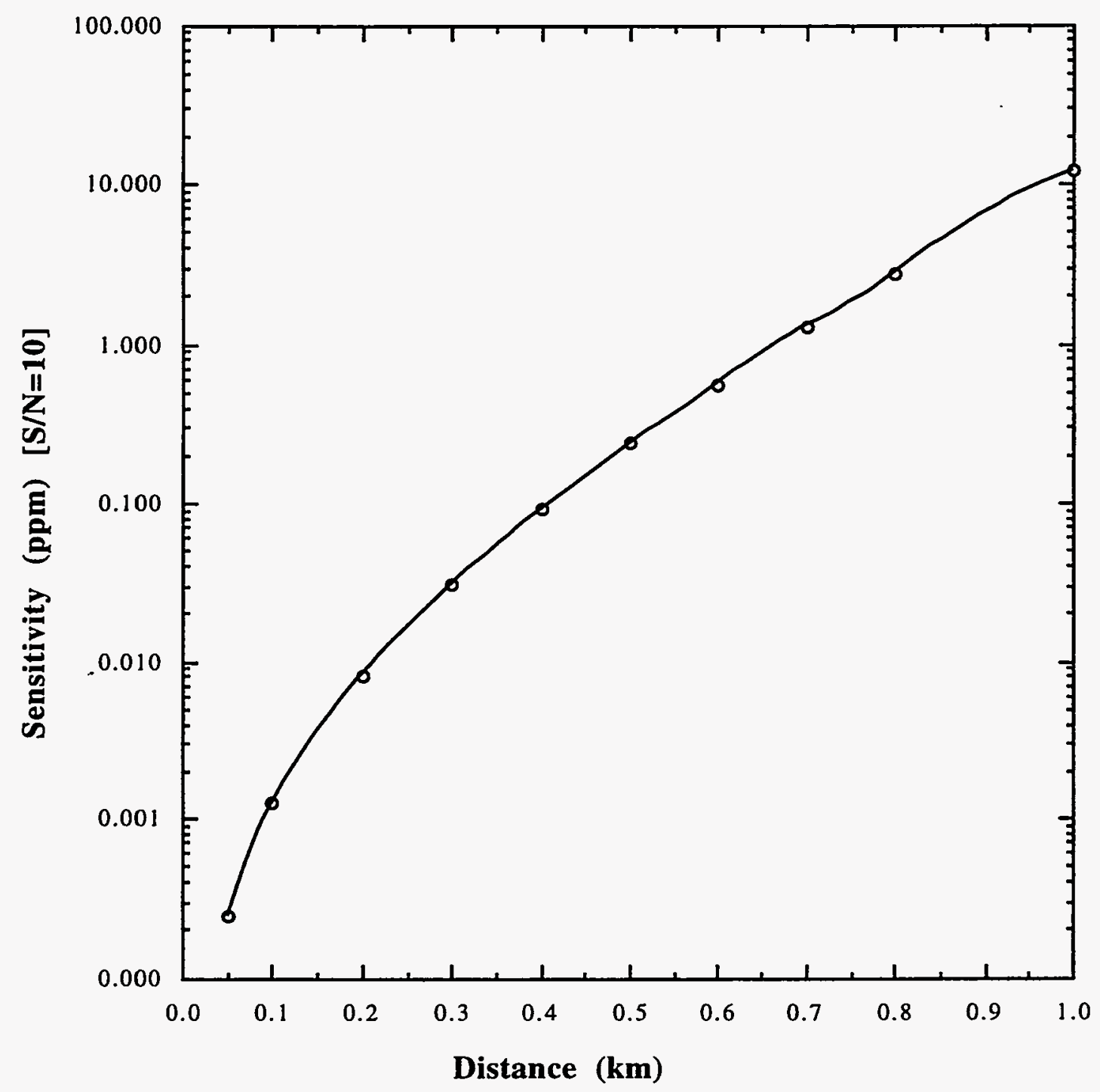

Figure 4.1. Sensitivity vs. range for $\mathrm{CCl}_{4}$ detection using the $v_{1}$ band. This calculation is based on the approach and assumptions used in Barletta. 12 The laser energy assumed was $400 \mathrm{~mJ} /$ pulse operating for a total of 50 pulses (exposure time $=0.1$ seconds at $500 \mathrm{~Hz}$ ). 
Based upon the considerations above, it would appear that the resonance enhancement of the Raman cross section of volatile organics particularly chloro-hydrocarbons is sufficiently high to permit the use of Raman spectroscopy as a trace detection method. This is true even for molecules such as $\mathrm{CCl}_{4}$ in which the lowest electronic absorption is a dissociative state. Based upon the results cf our experiments, it would appear that in situ analysis of VOCs is feasible especially given the short data acquisition times involved. More precise analysis of the spectrum could well yield further insights into the details of the excited state, however, such insights, although interesting, are probably not important in the development of an analytical method. Future effort directed towards the development of a suitable probe as well as a field-portable system would be desirable. Such effort could be directed towards the solution of a particular monitoring problem within a DOE waste remediation project. Once developed, however, it should be easily generalized to the analysis of other VOC's in other environments. 


\section{REFERENCES}

1. see, for example, C. L. Schoen, Laser Focus, 30(5), 113 (1994).

2. J. R. Lacher, L.E. Hummel, E. F. Bohmfalk and J. D. Park, J. Amer. Chem. Soc., 72, 5486-9 (1950).

3. K. Kaya, N. Mikami, Y. Udagawa, Chem. Phys. Lett., 13(3) 221-4 (1972).

4. H. Buyken, K. Klauss and H. Moser, Ber. der Bunsenges. Phys., 71 (6), 578-86 (1967). see also W. Hoffmann and H. Moser, Ber. der Bunsenges. Phys., 68 (2), 129-34 (1964).

5. H. Hase, K. Ishioka and T. Higashimura, Radiat. Phys. Chem., 38(1), 22-8 (1991).

6. G. Herzberg, Molecular Spectra and Molecular Structure, I. Spectra of Diatomic Molecules, 2nd edition, Princeton, 1950.

7. G. Herzberg, Molecular Spectra and Molecular Structure, II. Infrared and Raman Spectra of Polyatomic Molecules, Princeton, 1945.

8. D. T. Hamilton and F. F. Cleveland, J. Chem. Phys., 12(6), 24952(1944).

9. A. A. Gordus and R. B. Bernstein, J. Chem. Phys., 22(5),790$5(1954)$.

10. H. W. Schrötter and H. W. Klöckner, "Raman Scattering Cross Sections in Gases and Liquids", in Raman Spectroscopy of Gases and Liquids, A. Weber, ed. (Springer-Verlag, New York, 1979) pp. 12366.

11. T. H. Vickers, C. K. Mann, J. Zhu and C. K. Chong, Applied Spectroscopy Reviews, 26(4), 341-75(1991).

12. R. E. Barletta, Assessment of the Applicabilty of Raman Spectroscopy to the Detection of Chemical Agents, BNL-44846, July, 1990.

13. A. C. Eckbreth, Laser Diagnostics for Combustion Temperature and Species, (Abacus Press, Cambridge, 1988) 